\title{
Synthesis and Characterization of a Novel Diloop Macrocycle Substituted Phthalocyaninet
}

\author{
Halit Kantekin, İsmail Değirmencioğlu and Yaşar Gök* \\ Department of Chemistry, Karadeniz Technical University, 61080 Trabzon, Turkey
}

\begin{abstract}
Kantekin, H., Değirmencioğlu, İ. and Gök, Y., 1999. Synthesis and Characterization of a Novel Diloop Macrocycle Substituted Phthalocyanine. Acta Chem. Scand. 53: 247-252. (C) Acta Chemica Scandinavica 1999.

The novel metal-free and nickel phthalocyanines substituted peripherally with four 20-membered diazatetraoxa macrocycles each attached to a 15-membered crown ether moieties, have been synthesized in a multi-step reaction sequence. $N$-Tosylated derivatives are soluble in common organic solvents. The new compounds have been characterized by elemental analyses and by mass, IR, ${ }^{1} \mathrm{H}$ and ${ }^{13} \mathrm{C}$ NMR and UV-VIS spectroscopies.
\end{abstract}

The design, synthesis and functions of crown ethers and related macrocyles applicable to the construction of supramolecular assemblies are of great interest because of the wide range of applications of such assemblies, such as biosensors, molecular electronics and energy storage systems, as well as the biomimicking of natural systems and molecular recognition chemistry. ${ }^{1}$ In particular, the synthesis of crown ethers has grown enormously, giving chemists many opportunities to design new compounds and to investigate their applications. This kind of compound contains central hydrophilic cavities with either electronegative or electropositive binding atoms and an exterior flexible framework exhibiting hydrophobic behaviour. The selectivitiy of crown ethers towards alkali-metal cations has generally been explained in terms of 'hole-size selectivity' of the macrocyclic polyethers. However, in the case of a flat crown ether, such as dibenzo-18-crown-6, 'sandwich-type' $2: 1$ or 'club-sandwich-type' $3: 2$ complex formation with cations that are large in comparison with its cavity size is a common feature. ${ }^{2}$ It is obvious that in the case of benzo15-crown-5 cavity size is used in the extraction of the $\mathrm{Na}^{+}$cation owing to its compatibility with the radius of this cation, and it is also a fact that aza-crown-type macrocycles form strong coordinates with alkaline-earth metals. ${ }^{3}$ In the literature there are a few studies in which phthalocyanine-containing diloop macrocyclic structures are added. ${ }^{4 a}$ Metallophthalocyanine containing 15 crown $-5^{5}$ and 20 -membered macrocycle units are integral parts of the molecule, which is expected to result in the coordination of both alkali and alkaline-earth metal ions. On the other hand, phthalocyanines combined with

$\dagger$ Dedicated to Professor Özer Bekaroğlu on occasion of his 65th birthday.

* To whom correspondence should be addressed. crown ethers or related macrocycles ${ }^{6}$ are able to bind hard and soft metal cations to form homo- or heteropolynuclear complexes. Phthalocyanines have sufficiently stable rigid cores to permit the task of organizing binding sites in a definite structure. ${ }^{4 \mathrm{~b}}$ Besides their intrinsic use as dyes and pigments, phthalocyanines show a number of special properties ${ }^{7}$ which account for the present research interest and exciting future prospects. ${ }^{8}$

We have previously synthesized four dioxatetraaza ${ }^{9}$ or dioxatriaza $^{10}$ macrocycle-substituted phthalocyanines which are soluble in common organic solvents. Incorporation with 17-membered dioxatriaza macrocyclic moieties leads to products which additionally offer the advantage of extraction of alkaline-earth metal cations from aqueous solution to chloroform or dichloromethane media.

In the present paper we describe the synthesis of metalfree and metallophthalocyanines which contain four 20 membered diazatetraoxa macrocycles each attached to a 15-crown-5 moiety as two-layered substituents. Owing to phthalocyanine group, it is possible to form eight of the desired cavities in a single molecule. The combination of these two donor macrocycles can be expected to result in coordination of both alkali and alkaline-earth metal cations in the same molecule. On the other hand, in this study, in a single molecule, transition metal, alkali and alkaline-earth metals are combined with different donor groups, and thus a diloop macrocyclic structure selective against three different metal ions has been obtained.

\section{Results and discussion}

The ditosylated derivative of $4^{\prime}, 5^{\prime}$-diaminobenzo(15crown-5) (1) ${ }^{11}$ was treated with diethylene glycol monochlorohydrine (2) in dry DMF in the presence of anhydrous $\mathrm{K}_{2} 2 \mathrm{CO}_{3}$ as the base to give 8,9-benzo(15- 
crown-5)-7,10-di-(toluene- $p$-sulfonyl )-7,10-diaza-4,13dioxahexadecane-1,16-diol (3) in 76.5\% yield. As in the case of most other phthalocyanines containing macrocyclic moieties, a convenient method for similar compounds is to start with the dibromo or dicyano derivatives of the corresponding macrocyclic units. For this aim, the diloop macrocyclic compound, dibenzotetraoxadiazacyclodicontine, 20,21-dibromo-8,11-di(toluene- $p$ sulfonyl )-1,2,3,4,5,6,7,8,11,12,13,14,15,16,17,18-hexadecahydro-9,10-benzo( 15 -crown -5)-23,24 -benzo-2,5,14,17tetraoxa-8,11-diazacyclodicontine (5), was synthesized by the reaction of 1,2-dibromo-4,5-bis(bromomethyl)benzene (4) $)^{12}$ with 3 in a mixture of dry DMF-THF $(1: 1)$ and in the presence of potassium tertbutoxide (Scheme 1). The relatively high yield (48.9\%) of this macrocyclization reaction between two bifunctional reactants is a clear indication of the template effect of the potassium cation, ${ }^{13}$ while tosyl groups are also effective in this cyclization reaction: they are used as protective groups for the aza functions in the cyclotetramerization to obtain the phthalocyanine. ${ }^{14}$ Treatment with water at the end of the reaction was prevented, together with any difficulty which might have arisen from the presence of the potassium cation, which was formed by the decomposition of potassium carbonate as the template agent; no other adduct was formed between the crown ether unit and alkali metal cation.

The ${ }^{1} \mathrm{H}$ NMR spectrum of $\mathbf{3}$ showed that the product of this reaction consists of one subunit of $\mathbf{1}$ and two subunits of diol $\mathbf{2}$ in the form of a diol compound. The ${ }^{1} \mathrm{H}$ NMR spectrum of a $\mathrm{CDCl}_{3}$ solution of 3 was well resolved and showed that the formation of this macrocycle was accomplished. The chemical shifts belonging

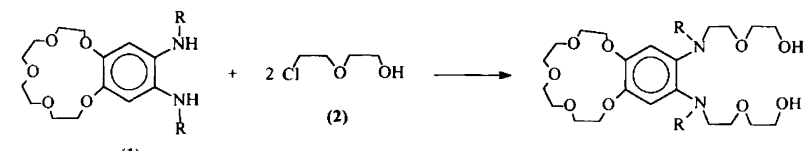

(1)

(3)

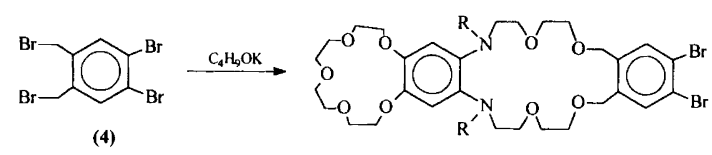

(5)

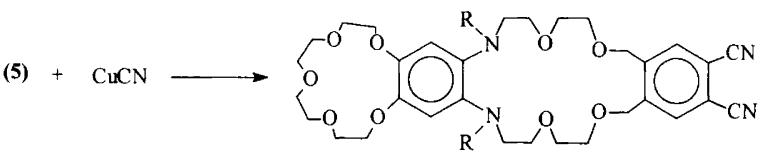

(6) to the deuterium-exchangeable $\mathrm{NH}$ groups at $\delta=$ $6.98 \mathrm{ppm}^{4 \mathrm{a}}$ disappear after the condensation reaction between 1 and 2 . The new resonances belonging to this compound appearing at $\delta=3.76-3.54$ and 2.59 ppm can be attributed to $\mathrm{CH}_{2} \mathrm{~N}$ and $\mathrm{CH}_{2} \mathrm{OH}$ resonances, respectively. The proton-decoupled carbon-13 NMR spectrum of $\mathbf{3}$ is consistent with the proposed formation. The chemical shifts for methylene carbon atoms adjacent to amine groups appeared at $\delta=42.80 \mathrm{ppm}$, when carbons next to the hydroxy group were found at $\delta=61.24 \mathrm{ppm}$. The IR spectrum of $\mathbf{3}$ exhibits sharp absorptions at $3224 \mathrm{~cm}^{-1}$, indicating $\mathrm{O}-\mathrm{H}$ stretching vibrations. On the other hand, the disappearance of the $\mathrm{N}-\mathrm{H}$ resonances is also in good agreement with the structure in Scheme 1. The fast atom bombardment mass spectrum of this compound (3) confirms the formation of the proposed compound $m / z=783[M+1]^{+}$and detosylated fragment; however, the peaks at $m / z=645\left[M-\text { tosyl }+\mathrm{H}_{2} \mathrm{O}\right]^{+}$and $490\left[M-2 \text { tosyl }+\mathrm{H}_{2} \mathrm{O}\right]^{+}$were formed, respectively. Elemetal analysis and ${ }^{1} \mathrm{H}$ - and ${ }^{13} \mathrm{C}$-NMR, IR and mass spectral data confirmed the structure of the 20 -membered diloop macrocyclic compound (5). The absence of the broad signal at $\delta=2.59 \mathrm{ppm}$ in the ${ }^{1} \mathrm{H}$ NMR spectra of $\mathbf{5}$ for the aliphatic $\mathrm{OH}$ groups of $\mathbf{3}$ showed that macrocyclization had occurred. In the ${ }^{1} \mathrm{H}$ NMR spectra, characteristic singlets for the benzylic protons appeared at $\delta=$ $4.55 \mathrm{ppm}$, and can be attributed to the completion of the cyclization reaction. More detailed information about the structure of 5 is provided by proton-decoupled carbon-13 NMR spectra. Absorptions for the carbon atoms bearing the benzylic groups are found at $\delta=$ $67.41 \mathrm{ppm}$ in the ${ }^{13} \mathrm{C}$ NMR spectra. These chemical shifts clearly indicate that cyclization has occurred. In the FAB mass spectrum concerning this diloop macrocyclic compound (5), a $M+1$ peak at $m / z=1043$ indicates that the proposed structure was formed. In the IR spectrum of 5, the disappearance of the stretching vibrations for aliphatic $\mathrm{O}-\mathrm{H}$ groups was assigned to the reaction between the diol group and the dibromo compound. The other vibrations belonging to the proposed compounds are very similar to those of the precursor compounds.

Copper phthalocyanine formation was accomplished either directly by the reaction of the precursor dibromocompound (5) with copper(I) cyanide in boiling quinoline or by the reaction of both compounds in pyridine in a sealed tube around at $220^{\circ} \mathrm{C}$ and purification by known procedures, or by converting the dibromo compound into the dicyano derivative (6) according to the Rosenmund-von Braun reactions, which might be considered to be an intermediate step in phthalocyanine formation, under milder conditions and then using this compound to synthesize the desired metal-free phthalocyanine and the corresponding metal salt (Scheme 1). ${ }^{15}$ Although the conversion of 5 into the dicyano derivative 6 is rather simple, its isolation is laborious. The critical point in this route was to isolate the 20,21-dicyanosubstituted diloop macrocyclic compound, which was accomp-

$$
\mathrm{R}=\mathrm{Ts}
$$

Scheme 1 
lished by keeping the concentration of the same reactants sufficiently low and by making use of a moderately highboiling solvent such as DMF or quinoline to avoid the formation of copper phthalocyaninate. ${ }^{16}$ In the IR spectrum of 6 , the intense absorption band appearing at $2229 \mathrm{~cm}^{-1}$ corresponds to the $\mathrm{C}=\mathrm{N}$ groups. The stretching vibrations observed at $704 \mathrm{~cm}^{-1}$, which belong to $\mathrm{C}-\mathrm{Br}$ absorptions, disappear after the conversion into the dicyano derivative. This resonance demonstrates that the desired conversion has occurred. The rest of the IR spectrum is closely similar to those of $\mathbf{5}$, including the characteristic vibrations of tosyl, aromatic and ether groups. The proton-decoupled carbon-13 NMR spectral data given in the Experimental section are also in accord with the expected structure. The $\mathrm{C}=\mathrm{N}$ groups of $\mathbf{6}$ are present as singlet at $\delta=112.03 \mathrm{ppm}$ in the ${ }^{13} \mathrm{C} \mathrm{NMR}$ spectra, indicating that they are substituted with the $\mathrm{C}-\mathrm{Br}$ groups in $\mathbf{5}$. The other chemical shifts belonging to aromatic, methyl, nitrile and crown or azaoxa crown carbons come out very close to those of precursor compound (5). In the FAB mass spectra, weak $\left[M+\mathrm{H}_{2} \mathrm{O}-1\right]^{+}$peaks are observed for this compound at $m / z=951$ and at $m / z=905$, together with strong $[M-2 \mathrm{~N}+1]^{+}$peaks, and this can be attributed to the substitution reaction which occurred between $\mathrm{C}-\mathrm{Br}$ with $\mathrm{CN}$ - in compound 6.

A great number of procedures ${ }^{17}$ were used for the synthesis of metal-free phthalocyanines, including direct interaction of the dicyano derivative $\mathbf{6}$, by heating $\mathbf{6}$ in 1 -pentanol at reflux temperature in the presence of a strong organic base such as 1,8-diaza-bicyclo[5.4.0]undec-7-ene (DBU). After the addition of $0.43 \mathrm{mmol}$ of the dicyano compound and DBU in dry 1-pentanol media, the reaction mixture was refluxed for about $24 \mathrm{~h}$ to complete the cyclotetramerization reaction by formation of the metal-free phthalocyanine (7). The yield of this reaction, in approximately $42 \%$, was rather high, and bulky groups did not result in any diffiulties as encountered for phthalocyanine with other groups. The most obvious feature of this compound is its extensive solubility in common organic solvents such as chloroform, dichloromethane, dimethyl sulfoxide, pyridine and dimethyl formamide. On the other hand, the solubilities in common organic solvents are higher than those of corresponding compounds containing only crown ether ${ }^{18}$ or dizatrioxa macrocyclic substituents. ${ }^{14}$ The diloop formation may result in a more bulky group, so solubility is enhanced. ${ }^{4}$

Spectral investigation of the newly synthesized metalfree phthalocyanine is in accord with the proposed structure (Scheme 1). The IR spectrum of 6 clearly indicates $\mathrm{CN}$ groups by the intense stretching vibrations at $2229 \mathrm{~cm}^{-1}$ as mentioned above. This disappears after conversion of 6 to 7, which shows an absorption at $3420 \mathrm{~cm}^{-1}$ for the $\mathrm{N}-\mathrm{H}$ groups due to the inner core. ${ }^{19}$ The ${ }^{1} \mathrm{H}$ NMR spectrum of 7 indicates aromatic protons at $\delta=7.95,7.82,7.32$ and $6.88 \mathrm{ppm}$ and aliphatic ether and $\mathrm{NCH}_{2}$ protons at $\delta=3.98-3.30 \mathrm{ppm}$, as well as the

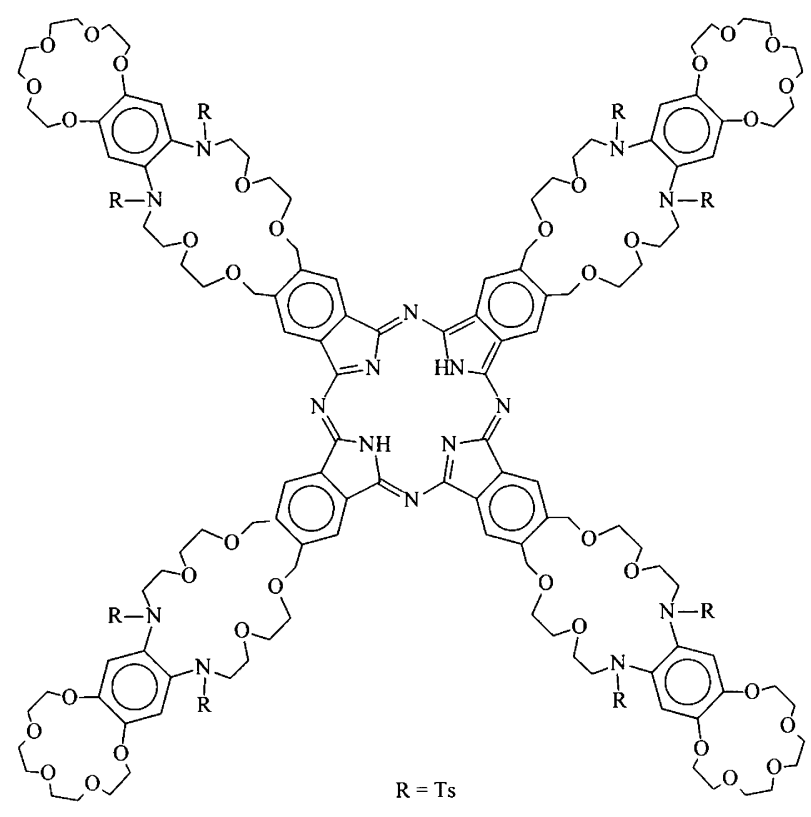

(7)

protons of the internal NH groups at $\delta=-4.71 \mathrm{ppm}$. This shift to higher field for the internal NH protons is a result of the $18 \pi$-electron system of the phthalocyanine core. The reported chemical shift values of internal $\mathrm{NH}$ groups for various substituted metal-free phthalocyanines vary from at $\delta=-2.00$ to $-9.00 \mathrm{ppm} .{ }^{20}$ However, the chemical shifts are rather small for the protons sufficiently far away from the ring current, such as $\mathrm{CH}_{2} \mathrm{O}$. Mass spectrometry is a powerful method for confirming the proposed structure of high molecular mass labile compounds such as phthalocyanines. ${ }^{21}$ Electrospray mass spectra of metal-free phthalocyanine (7) show peaks at $m / z=3913$ and 2852 which correspond to $[M+2(1-$ penthanol $)-1]^{+}$and $[M-6 \text { tosyl }-1]^{+}$, respectively, indicating that phthalocyanine formation has occurred.

The reaction of 6 in a high-boiling aprotic solvent such as quinoline with the appropriate metal salt $\left(\mathrm{Ni}^{\mathrm{II}}\right)$ gave the metallophthalocyanine. A mixture of dicyano compound $6, \mathrm{NiCl}_{2}$ and quinoline was heated and stirred at $200{ }^{\circ} \mathrm{C}$ under an argon atmosphere in a sealed glass tube for $8 \mathrm{~h}$. Column chromatography with silica gel was employed to obtain the pure product from the reaction mixture. The intense green product is very soluble in common organic solvents such as chloroform, dichloromethane, carbon tetrachloride, dimethyl formamide, dimethyl sulfoxide, etc. The high solubility of nickel phthalocyanine is due to the more bulky groups. The yield of nickel phthalocyanine $(12.8 \%)(8)$ was very low, as encountered for phthalocyanine with diloop bulky groups, in contrast to the formation of metal-free phthalocyanine (7).

Elemental analysis, and IR ${ }^{1} \mathrm{H}$ NMR, UV/VIS and mass spectral data confirm the proposed structure of nickel phthalocyanine. Cyclotetramerization of the dicyano compound (6) was confirmed by the disappearance 


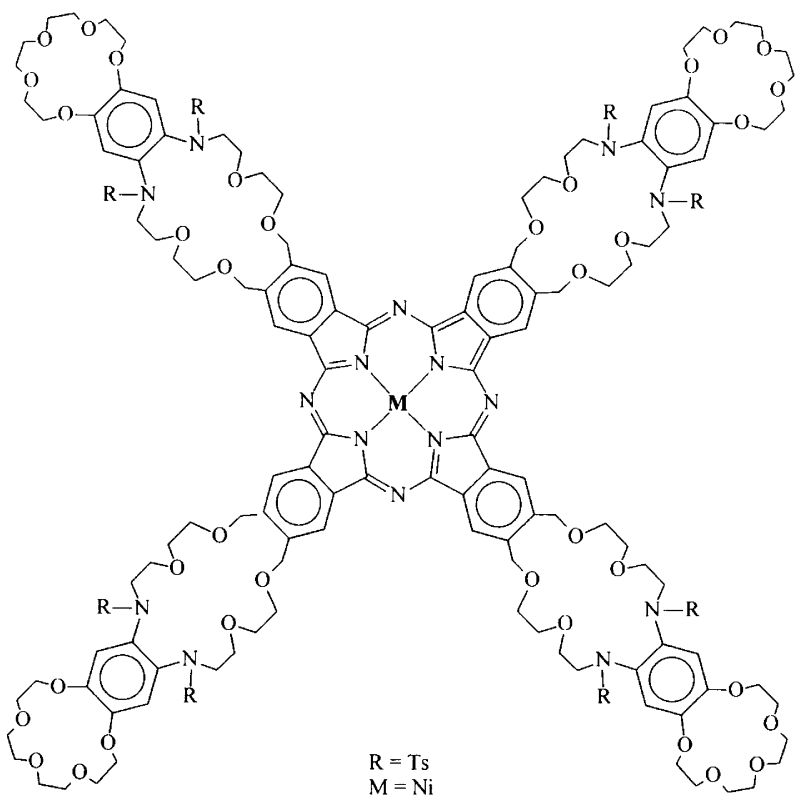

(8)

of the sharp $\mathrm{C}=\mathrm{N}$ vibration in the IR spectrum at $2229 \mathrm{~cm}^{-1}$ of the precursor compound. The ${ }^{1} \mathrm{H}$ NMR spectrum of nickel phthalocyanine and the metal-free species are almost identical, the basic difference being the disappearance of the broad $\mathrm{NH}$ protons of 7 at ca. $\delta=-4.71 \mathrm{ppm}$ in 8 . Also, the peaks of both spectra ( 7 and 8 ) are the broad absorptions probably caused by aggregation of the planar phthalocyanines, which is frequently encountered at the concentrations used for NMR measurements. ${ }^{8,22}$ Proton-decoupled ${ }^{13} \mathrm{C}$ NMR measurements have also been carried out, but a sufficient assignment of the signals was not obtained. The molecular ion peaks of compound $\mathbf{8}$ could not be detected by mass spectrometry at $m / z=3831$ due to $\left[M+2 \mathrm{H}_{2} \mathrm{O}+1\right]^{+}$.

The phthalocyanines $\mathbf{7}$ and $\mathbf{8}$ show typical electronic spectra with two strong absorption regions, one of them in the visible (VIS) at about $550-700 \mathrm{~nm}$ and the other in the ultraviolet (UV) portion at about $250-350 \mathrm{~nm}$. The monomeric species with $D_{4 \mathrm{~h}}$ symmetry in the metalfree derivative shows a single significant absorption in the Q-band region at $686 \mathrm{~nm},{ }^{23}$ which can be assigned to a $\pi \rightarrow \pi$ Q-band transition from the HOMO (Highest Occupied Molecular Orbital) to tha LUMO (Lowest Unoccupied Molecular Orbital) of the $\mathrm{Pc} 2 \mathrm{H}$ ring, and Soret-like $\pi \rightarrow \pi$ bands near $335 \mathrm{~nm}$ (B-band). ${ }^{24}$ The former intense band is especially important and will receive further attention for various near-IR applications. The characteristic Q-band has been considered as a probe in discussing the self-assembling features of phthalocyanines in solution. ${ }^{25}$ An increase in the concentration results in the aggregation of the phthalocyanine molecules, which is accompanied by a blue shift of the Q-band with some decrease in intensity that can be attributed to the monomeric species, with a simultaneous increase in the band at $639 \mathrm{~nm}$ being due to oligomeric aggregates. It is obvious that in dilute solutions (ca. $10^{-5} \mathrm{~mol}^{-3}$ ) the molecules are present as monomers in chloroform. Increasing the concentration leads to aggregation, which is easily monitored by the position of the Q-band, which shifts to shorter wavelengths and decreases the molar absorption coefficent. Nickel(II) phthalocyanine showed similar behaviour at lower energy; the Q-band appeared as an intense peak at $677 \mathrm{~nm}$ with a shoulder at around $645 \mathrm{~nm}$, corresponding to monomeric and aggregated forms in chloroform. ${ }^{26}$ Complexation with nickel(II) did not lead to appreciable changes in the Q-band and B-band regions in chloroform, as expected from the lowintensity $\mathrm{d}-\mathrm{d}$ transition.

\section{Experimental}

General. Routine infrared spectra were recorded on a Perkin-Elmer 1600 and a Mattson 1000 FTIR spectrometer as $\mathrm{KBr}$ pellets. UV-VIS spectra and elemental analysis were performed on a Unicam UV2-100 UV-VIS spectrophotometer and on a Hewlett-Packard $185 \mathrm{CHN}$ analyzer, respectively. ${ }^{1} \mathrm{H}$ and ${ }^{13} \mathrm{C}$ NMR spectra were recorded on a Varian-Gemini 200 spectrometer; $\dot{\delta}_{\mathrm{H}}$ values are relative to $\mathrm{Me}_{4} \mathrm{Si}, \delta_{\mathrm{C}}$ values reported are relative to $\mathrm{CDCl}_{3}$ at $\delta=77.0 \mathrm{ppm}$. Mass spectra and metal contents of the compounds were measured on a Kratos MS-50 triple analyzer and Concept $\mathrm{H}$ series mass spectrometer and a Unicam 929 AA spectrometer, respectively. All reagents were of analytical grade. Reactions were monitored by analytical TLC on cut strips of precoated plastic backed sheets (Merck silica gel 60 F254, $0.25 \mathrm{~mm}$ thickness). DMF was dried over $4 \mathrm{~A}$ and $13 \mathrm{X}$ molecular sieves and then distilled under reduced pressure. The other solvents were purified standard methods and THF was distilled from sodium ketyl benzophenone. Reactions were carried out under an inert atmosphere of nitrogen or argon. 4',5'-Diaminobenzo(15-crown-5), ${ }^{8} \quad 1,2$ dibromo-4,5-bis(bromomethyl) benzene ${ }^{9}$ and the ditosyl derivative of $4^{\prime}, 5^{\prime}$-diaminobenzo- $(15 \text {-crown-5 })^{4 a}$ were synthesized according to reported procedures. Melting points were determined by an Electrothermal apparatus and are uncorrected.

8,9-Benzo( 15-crown-5)-7,10-di(toluene-p-sulfonyl)-7,10diaza-4,13-dioxahexa-decane-1, 16-diol (3). Ditosyl derivative of 4',5'-diaminobenzo(15-crown-5) (1) (3.93 g, $6.50 \mathrm{mmol})$ was dissolved in dry DMF $(60 \mathrm{ml})$ containing finely ground anhydrous $\mathrm{K}_{2} \mathrm{CO}_{3}(10 \mathrm{~g}$, $7.2 \mathrm{mmol})$ in excess and stirred under a nitrogen atmosphere at $40^{\circ} \mathrm{C}$ for $1 \mathrm{~h}$. A solution of diethyleneglycohol monochlorhydrine (2) $(1.40 \mathrm{~g}, 12.9 \mathrm{mmol})$ in dry DMF $(10 \mathrm{ml})$ was added dropwise over $2 \mathrm{~h}$ and stirred continuously at the same temperature for $96 \mathrm{~h}$. The end of the reaction was determined by thin-layer chromatography [ $n$-butanol:acetic acid: water $(4: 1: 5)$ ]. After cooling to room temperature, the solution was evaporated to dryness under reduced pressure and was then poured slowly on to ice (400 g) and stirred overnight. The crude product 
was filtered off, washed with water and cold ethanol and then dried in vacuo. The solid product was recrystallized from a mixture of ethanol and chloroform $(1: 2)$ to yield pale yellow crystals $(3.9 \mathrm{~g}, 76.5 \%)$, m.p. $230-232{ }^{\circ} \mathrm{C} .{ }^{1} \mathrm{H}$ NMR $\left(\mathrm{CDCl}_{3}\right) \delta: 7.51(\mathrm{t}, 4 \mathrm{H}, \mathrm{Ar}-\mathrm{H}), 7.23(\mathrm{~m}, 4 \mathrm{H}$, $\mathrm{Ar}-\mathrm{H}), 6.62$ (s, $2 \mathrm{H}, \mathrm{Ar}-\mathrm{H}), 3.76-3.54\left(\mathrm{~m}, 32 \mathrm{H}, \mathrm{CH}_{2} \mathrm{O}\right.$, $\left.\mathrm{CH}_{2} \mathrm{~N}\right), 2.59(\mathrm{~s}, 2 \mathrm{H}, \mathrm{C}-\mathrm{OH}), 2.51\left(\mathrm{~s}, 3 \mathrm{H}, \mathrm{CH}_{3}\right)$, $2.33\left(\mathrm{~s}, 3 \mathrm{H}, \mathrm{CH}_{3}\right) .{ }^{13} \mathrm{C} \mathrm{NMR}\left(\mathrm{CDCl}_{3}\right) \delta: 145.44$, $143.77, \quad 140.14,131.40,130.94,128.50,109.36$, 71.68-70.32, 61.24, 42.80, 22.70. IR ( $\mathrm{KBr}$ pellets, $\mathrm{cm}^{-1}$ ): $3224(\mathrm{O}-\mathrm{H}), 3042(\mathrm{Ar}-\mathrm{H}), 2924(\mathrm{C}-\mathrm{H}), 1597,1559$, $1499,1362,1209-1082,668,547$. Mass spectrum (FAB): $m / z=783 \quad[M+1]^{+}, \quad 645 \quad\left[M-\text { tosy }+\mathrm{H}_{2} \mathrm{O}\right]^{+}, \quad 490$ $\left[M-2 \text { tosyl }+\mathrm{H}_{2} \mathrm{O}\right]^{+}$. Found: $\mathrm{C}, 55.38 ; \mathrm{H}, 6.17 ; \mathrm{N}, 3.41$. Calc. for $\mathrm{C}_{36} \mathrm{H}_{50} \mathrm{~N}_{2} \mathrm{O}_{13} \mathrm{~S}_{2}$ : C, 55.24; $\mathrm{H}, 6.39 ; \mathrm{N}, 3.58$.

20,21 -Dibromo-8,11-di( toluene-p-sulfonyl) -1,2,3,4,5,6,7, $8,11,12,13,14,15,16,17,18$ - hexadeca - hydro - 9,10 - benzo (15-crown-5)-23,24-benzo-2,5,14,17-tetraoxa-8,11-diazacyclodicontine (5). Compound $3(3.0 \mathrm{~g}, 3.8 \mathrm{mmol})$ was dissolved in dry DMF $(250 \mathrm{~m})$ under nitrogen, and potassium tert-butoxy $(4.3 \mathrm{~g}, 38.3 \mathrm{mmol})$ in dry THF $(200 \mathrm{ml})$ was added at $50^{\circ} \mathrm{C}$, then the reaction mixture was allowed to stand at the same temperature for $3 \mathrm{~h}$. A solution of 1,2-dibromo-4,5-bis(bromomethyl)benzene (4) $(1.6 \mathrm{~g}, 3.8 \mathrm{mmol})$ in dry THF $(50 \mathrm{ml})$ was added dropwise over $8 \mathrm{~h}$ and stirred at the same temperature, then the reaction mixture was heated and stirred at $95^{\circ} \mathrm{C}$ for $83 \mathrm{~h}$. The reaction was monitored by TLC $\left[\mathrm{CHCl}_{3}\right.$ : $\left.\mathrm{MeOH}: \mathrm{H}_{2} \mathrm{O}(75: 23: 2)\right]$. At the end of this period, the reaction mixture was evaporated to dryness, and icewater $(450 \mathrm{~g})$ was added to this residue and then stirred overnight at room temperature. The mixture was decanted several times; then the oily residue was extracted with $\mathrm{CHCl}_{3}(3 \times 50 \mathrm{ml})$ and the combined organic layers were washed several times with an aqueous solution of $\mathrm{K}_{2} \mathrm{CO}_{3}(5 \%)$ and water. The organic extract was dried over $\mathrm{Na}_{2} \mathrm{SO}_{4}$ and concentrated under reduced pressure to $20 \mathrm{ml}$ and then cooled to $-18^{\circ} \mathrm{C}$; a brown solid product was obtained which was filtered off, washed with cold ethanol and diethyl ether and then dried in vacuo. The crude product was recrystallized from ethanol to yield pale brown crytals $(1.95 \mathrm{~g}, 48.9 \%)$, m.p. $125-127^{\circ} \mathrm{C} .{ }^{1} \mathrm{H}$ NMR $\left(\mathrm{CDCl}_{3}\right) \delta: 8.95(\mathrm{~s}, 2 \mathrm{H}, \mathrm{Ar}-\mathrm{H})$, $7.54(\mathrm{t}, 4 \mathrm{H}, \mathrm{Ar}-\mathrm{H}), 7.34(\mathrm{t}, 4 \mathrm{H}, \mathrm{Ar}-\mathrm{H}), 6.43$ (s, $2 \mathrm{H}$, $\mathrm{Ar}-\mathrm{H}), 4.55\left(\mathrm{~s}, 4 \mathrm{H}, \mathrm{CH}_{2}-\mathrm{Ar}\right), 4.06-3.28(\mathrm{~m}, 32 \mathrm{H}$, $\left.\mathrm{CH}_{2} \mathrm{O}, \mathrm{CH}_{2} \mathrm{~N}\right), 2.51$ (s, $\left.3 \mathrm{H}, \mathrm{CH}_{3}\right), 2.36\left(\mathrm{~s}, 3 \mathrm{H}, \mathrm{CH}_{3}\right)$. ${ }^{13} \mathrm{C}$ NMR $\left(\mathrm{CDCl}_{3}\right) \delta: 147.96,145.40,137.62,131.41$, $129.40, \quad 128.87, \quad 127.59, \quad 125.19, \quad 112.03,104.39$, 72.04-70.19, 67.41, 32.41, 22.77. IR ( $\mathrm{KBr}$ pellets, $\mathrm{cm}^{-1}$ ): 3063 (Ar-H), 2919 (C-H), 1599, 1515, 1346, 1207-1089, $814,704,668,545$. Mass spectrum (FAB): $m / z=1043$ $[M+1]^{+}, 1099\left[M+\mathrm{K}+\mathrm{H}_{2} \mathrm{O}\right]^{+}$. Found: $\mathrm{C}, 50.81 ; \mathrm{H}$, 5.02; N, 2.87. Calc. for $\mathrm{C}_{44} \mathrm{H}_{54} \mathrm{~N}_{2} \mathrm{O}_{13} \mathrm{~S}_{2} \mathrm{Br}_{2}$ : C, 50.67; H, $5.18 ; \mathrm{N}, 2.68$.

20,21 -Dicyano-8,11 -di( toluene -p -sulfonyl) -1,2,3,4,5,6,7, $8,11,12,13,14,15,16,17,18$-hexadeca-hydro-9,10-benzo( 15 - crown-5)-23,24-benzo-2,5,14,17-tetraoxa-8,11-diazacyclodicontine (6). Compound 5 (1.34 g, $1.3 \mathrm{mmol})$ was dissolved in dry DMF $(6 \mathrm{ml})$ containing CuCN $(0.35 \mathrm{~g}$, $3.9 \mathrm{mmol})$ and stirred under an argon atmosphere at $175^{\circ} \mathrm{C}$; it was then refluxed at the same temperature for $12 \mathrm{~h}$ with addition of a catalytic amount of pyridine. During this period, the solution became dark browngreen. After cooling to room temperature, the reaction mixture was poured into aqueous $\mathrm{NH}_{4} \mathrm{OH}(25 \%$, $150 \mathrm{ml}$ ), and air was passed through the mixture for $24 \mathrm{~h}$. The reaction mixture was filtered through Celite and washed with dilute aqueous $\mathrm{NH}_{4} \mathrm{OH}(10 \%)$ several times and then with water until the filtrate was neutral. The solid product was dried in vacuo and purified by column chromatography (eluting with acetone-chloroform, 1:1) to give the dicyano compound (6). The solvent mixture was evaporated under vacuum to yield a cream-coloured product $(0.82 \mathrm{~g}, 68.3 \%)$, m.p. $80-82{ }^{\circ} \mathrm{C}$. ${ }^{1} \mathrm{H}$ NMR (DMSO-d ${ }_{6}$ ) $\delta: 7.88(\mathrm{~s}, 2 \mathrm{H}, \mathrm{Ar}-\mathrm{H}), 7.47(\mathrm{t}$, $4 \mathrm{H}, \mathrm{Ar}-\mathrm{H}), 7.25$ (t, $4 \mathrm{H}, \mathrm{Ar}-\mathrm{H}), 6.48(\mathrm{~s}, 2 \mathrm{H}, \mathrm{Ar}-\mathrm{H})$, $4.65\left(\mathrm{~s}, 4 \mathrm{H}, \mathrm{CH}_{2}-\mathrm{Ar}\right), 3.95-3.23\left(\mathrm{~m}, 32 \mathrm{H}, \mathrm{CH}_{2} \mathrm{O}\right.$, $\left.\mathrm{CH}_{2} \mathrm{~N}\right), 2.50\left(\mathrm{~m}, 6 \mathrm{H}, \mathrm{CH}_{3}\right) \cdot{ }^{13} \mathrm{C} \mathrm{NMR}\left(\mathrm{DMSO}_{6}\right) \delta$ : $149.19,147.34,143.58,138.28,132.43,131.68,129.55$, $127.05,112.03,108.53,102.84,72.30-70.38,66.18,32.42$, 22.81. IR ( $\mathrm{KBr}$ pellets, $\left.\mathrm{cm}^{-1}\right): 3057(\mathrm{Ar}-\mathrm{H}), 2918$ $(\mathrm{C}-\mathrm{H}), 2229$ (C=N), 1596, 1560, 1508, 1344, 1210-1089, 936, 814, 668, 544. Mass spectrum (FAB): $m / z=951$ $\left[M+\mathrm{H}_{2} \mathrm{O}-1\right]^{+}, 905[M-2 \mathrm{~N}+1]^{+}$. Found: C, 58.94; $\mathrm{H}$, 5.95; N, 6.22. Calc. for $\mathrm{C}_{46} \mathrm{H}_{54} \mathrm{~N}_{4} \mathrm{O}_{13} \mathrm{~S}_{2}$ : C, 59.10; $\mathrm{H}$, $5.78 ; \mathrm{N}, 5.99$.

Metal-free [octakis ( N-p-tosyl)tetrakis (diloopmacrocycle)phthalocyanine] (7). A mixture of the dicyano derivative of macrocycle $6(0.40 \mathrm{~g}, 0.43 \mathrm{mmol})$, dry $n$-amyl alcohol $(13 \mathrm{ml})$ and 5 drops of DBU was placed in a Schlenk tube under argon, gently heated, and subsequently heated at $140^{\circ} \mathrm{C}$ for $24 \mathrm{~h}$. After cooling to room temperature a dark green oil was obtained. This oily product was washed several times with water and cold ethanol to remove the unreacted organic material, and then the solidified yield was dried in vacuo. The crude product and methanol $(50 \mathrm{ml})$ were placed in a round-bottommed flask and refluxed for $6 \mathrm{~h}$. The heated solution was filtered off, washed with ethanol and concentrated to $20 \mathrm{ml}$ under reduced pressure. Water was added dropwise to this solution until precipitation occurred. The resulting dark-green precipitate was filtered off, washed with cold ethanol and ethyl ether and then dried in vacuo to yield a dark-green solid $(0.17 \mathrm{~g}, 41.9 \%)$, m.p. 113-114 ${ }^{\circ} \mathrm{C} .{ }^{1} \mathrm{H}$ NMR $\left(\mathrm{CDCl}_{3}\right) \delta: 7.95(\mathrm{~s}, 8 \mathrm{H}, \mathrm{Ar}-\mathrm{H})$, $7.82(\mathrm{~m}, 16 \mathrm{H}, \mathrm{Ar}-\mathrm{H}), 7.32(\mathrm{~m}, 16 \mathrm{H}, \mathrm{Ar}-\mathrm{H}), 6.88(\mathrm{~s}$, $8 \mathrm{H}, \mathrm{Ar}-\mathrm{H}), 4.98$ (s, $\left.16 \mathrm{H}, \mathrm{CH}_{2}-\mathrm{Ar}\right), 3.98-3.30$ (m, $128 \mathrm{H}, \mathrm{CH}_{2} \mathrm{O}, \mathrm{CH}_{2} \mathrm{~N}$ ), 2.41 (s, $24 \mathrm{H}, \mathrm{CH}_{3}$ ), -4.71 (s, $2 \mathrm{H}, \mathrm{NH})$. IR ( $\mathrm{KBr}$ pellets, $\left.\mathrm{cm}^{-1}\right): 3420(\mathrm{~N}-\mathrm{H}), 3054$ $(\mathrm{Ar}-\mathrm{H}), 2918(\mathrm{C}-\mathrm{H}), 1600,1560,1508,1489,1321$, 1213-1094, 940, 812, 668, 502. UV-VIS $\left(\mathrm{CCl}_{3}, \log \varepsilon\right)$ : $\lambda_{\max } 686$ (4.12), 639 (3.75), 620 (3.85), 586 (3.71), 335 (4.17), 272 (4.29), 240 (4.65). Mass spectrum 
(Electrospray): $\quad m / z=3913[M+2(1 \text {-pentanol })-1]^{+}$, $2852[M-6 \text { tosyl }-1]^{+}$. Found: C, 59.33; H, 5.62; N, 5.71. Calc. for $\mathrm{C}_{184} \mathrm{H}_{218} \mathrm{~N}_{16} \mathrm{O}_{52} \mathrm{~S}_{8}: \mathrm{C}, 59.06 ; \mathrm{H}, 5.83$; N, 5.99 .

[Octakis( $\mathrm{N}$ - p-tosyl) tetrakis (diloopmacrocycle) phthalocyaninato/nickel(II) (8). A mixture of the dicyano derivative of diloopmacrocycle $6(0.36 \mathrm{~g}, 0.08 \mathrm{mmol})$, purified quinoline $(3 \mathrm{ml})$ and $\mathrm{NiCl}_{2} \cdot 6 \mathrm{H}_{2} \mathrm{O}(0.30 \mathrm{~g}, 0.33 \mathrm{mmol})$ was placed a round-bottommed flask under argon which was fitted with a stir-bar and condenser, and then immersed in an oil bath. The bath temperature was brought to $200^{\circ} \mathrm{C}$ during $1 \mathrm{~h}$ and stirred at that temperature for $8 \mathrm{~h}$. The resulting dark-green suspension was cooled to room temperature and diluted with methanol, then filterd off, washed successively with methanol, acetone, heptane and acetone in order. The filtrate was purified by column chromatography [silica gel, $\mathrm{CHCl}_{3}$ $\left.\mathrm{CH}_{2} \mathrm{Cl}_{2}-\mathrm{EtOH}(2: 1: 1)\right]$ and added dropwise into stirred ethyl acetate $(200 \mathrm{ml})$. The resulting dark-green precipitate was filtered off, washed with ethyl acetate and diethyl ether and then dried in vacuo to yield dark-green solid $(0.04 \mathrm{~g}, 12.8 \%) .{ }^{1} \mathrm{H}$ NMR spectrum $\left(\mathrm{CDCl}_{3}\right) \delta: 8.05$ (s, $8 \mathrm{H}, \mathrm{Ar}-\mathrm{H}), 7.78(\mathrm{~m}, 16 \mathrm{H}, \mathrm{Ar}-\mathrm{H}), 7.61(\mathrm{~m}, 16 \mathrm{H}$, $\mathrm{Ar}-\mathrm{H}), 6.53(\mathrm{~s}, 8 \mathrm{H}, \mathrm{Ar}-\mathrm{H}), 4.82\left(\mathrm{~s}, 16 \mathrm{H}, \mathrm{CH}_{2}-\mathrm{Ar}\right)$, 4.11-3.43 (m, $\left.128 \mathrm{H}, \mathrm{CH}_{2} \mathrm{O}, \mathrm{CH}_{2} \mathrm{~N}\right), 2.48(\mathrm{~s}, 24 \mathrm{H}$, $\left.\mathrm{CH}_{3}\right)$. IR ( $\mathrm{KBr}$ pellets, $\left.\mathrm{cm}^{-1}\right): 3058(\mathrm{Ar}-\mathrm{H}), 2921$ (C-H), 1596, 1570, 1508, 1340, 1180-1089, 933, 814, 668, 548. UV-VIS $\left(\mathrm{CHCl}_{3}, \log \varepsilon\right): \lambda_{\max } 677(4.86), 645$ (4.38), 627 (4.26), 611 (4.30), 545 (3.91), 340 (4.25), 279 (3.98), 245 (4.43): Mass spectrum (Electrospray): $m / z=3831\left[M+2 \mathrm{H}_{2} \mathrm{O}+1\right]^{+}$. Found: C, 58.04; $\mathrm{H}, 5.88$; $\mathrm{N}, 6.13 ; \mathrm{Ni}$, 1.39. Calc. for $\mathrm{C}_{184} \mathrm{H}_{216} \mathrm{~N}_{16} \mathrm{O}_{52} \mathrm{~S}_{8} \mathrm{Ni}$ : C, $58.18 ; \mathrm{H}, 5.69 ; \mathrm{N}, 5.90 ; \mathrm{Ni}, 1.54$.

Acknowledgements. We thank the Reseach Fund of the Karadeniz Technical University for financial support of the research project. We are also indebted to Dr. R. D. W. Kemmit (University of Leicester, UK) and Professor C. C. Leznoff (York University, Canada) for their assistance related to mass spectral data.

\section{References}

1. Tsukube, H. Coord. Chem. Rev. 148 (1996) 1.

2. Kobiro, K. Coord. Chem. Rev. 148 (1996) 135; Pedersen, C. J. J. Am. Chem. Soc. 89 (1967) 7017.

3. Gök, Y. and Atalay, Y. J. Inc. Phenom. 28 (1997) 287; Bajaj, A. V. and Poonia, N. S. Coord. Chem. Rev. 87 (1988) 55

4. (a) Koçak, M., Okur, A. I. and Bekaroglu, Ö. J. Chem. Soc., Dalton Trans. (1994) 233; (b) Piechocki, C. and Simon, J. Nouv. J. Chim. 9 (1985) 159.
5. Ishikawa, N. and Kaizu, Y. Chem. Lett. (1988) 183; Xu, H. J. and Xiong, G. X. J. Photochem. Photobiol. A-Chem. 92 (1995) 35.

6. Ishikawa, N. and Kaizu, Y. Mol. Cryst. Liquid Cryst. 285 (1996) 585; Xiong, G. X., Shen, S. Y., Ye, J. P., Zhou, Q. F., et al. Chin. J. Chem. 15 (1997) 443; Özdemir, M. and Ağar, E. Spectrosc. Lett. 24 (1991) 741.

7. Kobayashi, N., Togashi, M., Osa, T., Ishii, K., et al. J. Am. Chem. Soc. 118 (1996) 1073; Jory, M. J., Cann, P. S., Sambles, J. R. J. Phys. Appl. Phys. 27 (1994) 169; Anzai, J. I. and Liu, C. C. Polym. Commun. 31 (1990) 223; Sielcken, O. E., Vandekuil, L. A., Drenth, W., Schoonman, J., et al. J. Am. Chem. Soc. 112 (1990) 3086.

8. Leznoff, C. C. and Lever, A. B. P., Eds. Phthalocyanines, Properties and Application, VCH, Weinheim 1989, Vol. 1, 1993, Vol. 2; Tan, N., Bekaroglu, Ö. and Kadırgan, F. J. Electroanal. Chem. 364 (1994) 251; Bekaroglu, Ö. Appl. Organomet. Chem. 10 (1996) 605.

9. Gök, Y. and Yıldız, S. Z. J. Coord. Chem. 36 (1995) 175; Gök, Y. and Yıldız, S. Z. Polyhedron 16 (1997) 113.

10. Gök, Y. and Yildı, S. Z. Polyhedron 16 (1997) 2335.

11. Gök, Y. Org. Prep. Proc. Int. 22 (1990) 641.

12. Piechocki, C. and Simon, J. Nouv. J. Chem. 9 (1985) 159.

13. Chavez, F. and Sherry, A. D. J. Org. Chem. 54 (1989) 2990.

14. Gümüş, G., Öztürk, Z. Z., Ahsen, V., Gül, A. and Bekaroglu, Ö. J. Chem. Soc., Dalton Trans. (1992) 2485.

15. Rosenmund, K. W. and Struck, E. Ber. Dtsch. Chem. Ges. 52 (1919) 1749; Braun, V. J. and Manz. G. Liebigs Ann. Chem. 488 (1931) 116.

16. Ahsen, V., Yılmazer, E., Erbaş, M. and Bekaroglu, Ö. J. Chem. Soc., Dalton Trans. (1988) 401.

17. Tomoda, H., Saito, S., Ogawa, S. and Shiraishi, S. Chem. Lett. (1980) 1277; Koçak, M., Gürek, A., Gül, A. and Bekaroglu, Ö. Chem. Ber. 127 (1994) 355.

18. Ahsen, V., Yılmazer, E., Erbaş, M. and Bekaroglu, Ö. J. Chem. Soc., Dalton Trans. (1988) 401; Okur, A. İ., Gül, A., Cihan, A., Tan, N. and Bekaroglu, Ö. Synth. React. Inorg. Met.-Org. Chem. 20 (1990) 1399; Ahsen, V., Yılmazer, E., Gürek, A., Gül, A. and Bekaroglu, Ö. Helv. Chim. Acta 71 (1988) 1616.

19. Gürek, A. and Bekaroglu, Ö. Helv. Chim. Acta 77 (1994) 1616.

20. Snow, A. W., Griffith, J. R. and Marullo, N. P. Macromolecules 17 (1984) 1614; Piechocki, C. and Simon, J. Nouv. J. Chim. 9 (1985) 159; Hirsch, A. and Hanack, M. Chem. Ber. 124 (1991) 833.

21. Aubagnac, J. L., Münster, H., Elguero, J. and Meutermans, W. Rapid Commun. Mass Spectrum 6 (1992) 540.

22. Gürol, İ., Ahsen, V. and Bekaroglu, Ö. J. Chem. Soc., Dalton Trans. (1994) 497.

23. Musluoglu, E. and Bekaroglu, Ö. J. Chem. Research (S) (1994) 420.

24. Yılmaz, İ. and Bekaroglu, Ö. Chem. Ber. 129 (1996) 967.

25. Gürek, A. and Bekaroglu, Ö. J. Chem. Soc., Dalton Trans. (1994) 1419.

26. Gök, Y. and Yildiz, S. Z. J. Coord. Chem. 36 (1995) 175; Kobayashi, N. and Nishiyama, Y. J. Chem. Soc., Chem. Commun. (1986) 1462.

Received July 1, 1998. 